\title{
Causes of Decline and Potential for Recovery of Atlantic Cod Populations
}

\author{
Ray Hilborn ${ }^{1}$ and Emilie Litzinger ${ }^{2,3 *}$ \\ ${ }^{1}$ University of Washington, USA; ${ }^{2}$ School of Marine Affairs, University of Washington 1707 Brooklyn Avenue NE, Seat- \\ tle, WA 98105-6715 USA; ${ }^{3}$ Environmetal Defense Fund, 18 Tremont Street, Suite 850, Boston, MA 02108, USA
}

\begin{abstract}
The large declines in abundance and failure to recover in many Atlantic cod populations has been the subject of numerous papers and the continued low abundance of several Canadian cod populations has become an icon for failed fisheries management. It has been argued that many stocks failed to recover after declines, despite reduced fishing pressure. A range of complex mechanisms have been invoked to explain failure to recover, including decreased age-atmaturity, vulnerability to by-catch, fishing induced evolution, depensatory predation and habitat change caused by fishing gear. We show that, for all North East Atlantic cod populations, continued high fishing pressure is sufficient to explain the failure of stocks to recover and the stocks would increase at $40-60 \%$ per year in the absence of fishing. This is also true for four out of nine North American cod stocks. The other five North American stocks, located in the Gulf of St Lawrence and around the Grand Banks and Labrador, show no net productivity (would not increase in the absence of fishing) since the late 1980s or early 1990s. Four of the Canadian stocks show a rapid shift in the mid 1980s, from being highly productive to low or negative net productivity, despite having been at relative high abundance. We conclude that for most Atlantic cod stocks (13 out of 18) no mechanism other than excessive fishing is required to explain their failure to recover. Fishing pressure cannot lead to the sudden decrease in productivity in the four Canadian stocks which flipped from high to low productivity; environmental change seems the likely cause, although continued fishing drove these stocks to very low abundance and likely impaired their ability to recover.
\end{abstract}

\section{INTRODUC TION}

The decline of fish stocks has become one of the principal concerns of fisheries management in the last 15 years, and two studies have performed meta-analysis of the frequency of stock decline and recovery $[1,2]$. Both Hilborn and Hutchings note that while severe declines were common across many fish taxa, recoveries were much more common in the pelagics (sardines, herring, mackerel), than in the gadids (cods, hake). Indeed the decline of cod stocks (Gadus morhua) around the Atlantic, and in Canada in particular, have become symbols of failed fisheries management. Hutchings [2] and Hutching and Reynolds [3] have argued that the recovery of fish stocks from low abundance despite reduced fishing pressure is "surprisingly" slow and suggest that there may be numerous ecological mechanisms that change at low abundance. "Unprecedented reductions in abundance and surprisingly low rates of recovery draw attention to scientists' limited understanding of how fish behavior, habitat, ecology, and evolution affect population growth at low abundance" [3].

In the last 10 years a series of papers have explored a range of hypotheses to explain the overall failure of Canadian cod stocks to rebuild. Swain and Sinclair [4] argued that higher abundance of pelagic fish led to more predation on juvenile cod. Fu et al. [5] explored predation as a mechanism for one (4VSW) Canadian stock and concluded that it could not explain the decline in the 1980s, but might explain the failure to recover in the 1990s. In contrast, Chouinard et al.

*Address correspondence to this author at the Box 355020 University of Washington, Seattle WA 98195 USA; Tel: 206543 3587;

E-mail: rayh@u.washington.edu
[6] found evidence that increased seal abundance had led to higher natural mortality rates in the southern Gulf of St. Lawrence. Olsen [7] supported earlier maturation as a factor, Swain et al. [8] suggested reduced somatic growth rates, Rothschild et al. [9] argued for coherent environmental causes, Hutchings and Reynolds [3] suggested that there a wide range of possible mechanisms, and Walters and Kitchell [10] identified cultivation-depensation as possibly playing a major role in the failure to recover.

Dutil et al. [11], noting that net production went to zero in the Northern Gulf of St. Lawrence in the mid 1980s, evaluated changes in somatic growth, mortality and recruitment. Dutil and Brander [12] looked in detail at geographic variation in rates of surplus production, and found considerable geographic variation. On the one hand there are numerous studies dealing with stock-specific processes on individual cod stocks, while others, notably Rothschild [9], explore the larger picture across a range of stocks.

Perhaps the simplest view of the population dynamics is to track changes in total biomass that can be written as

$$
B_{y+1}=B_{y}+P_{y}-C_{y}
$$

Where $B_{y}, P_{y}$ and $C_{y}$ are, respectively, the stock biomass, net production and catch in year $y$. Net productivity is the result of the processes or recruitment, survival from natural mortality and somatic growth. This formulation was used to judge the overall dynamics of populations by Hilborn [13] for monkfish, and by Jacobson et al. [14] for sardines and anchovy; recently Walters et al. [15] have explored the trends in surplus production for over 100 stocks during population decline and recovery. 
The key question in the dynamics of a fish population is how surplus production is related to stock size. Hutchings argument that gadid stocks recover surprisingly slowly when fishing pressure is removed essentially claims that the rate of surplus production (the ratio of $\mathrm{P}$ to $\mathrm{B}$ ) declines at low $\mathrm{B}$. Complex hypotheses of genetic change and depensatory predation are mechanisms to explain why rates of productivity decline at low abundance. Myers et al. [16] and Liermann and Hilborn [17] both explored depensation in the recruitment process using the original Myers data base and found little evidence that rates of recruitment declined at low abundance. However, some of the causes of decline in surplus production could be due to declines in somatic growth or increases in natural mortality of recruited fish, and analysis of surplus production may be a more powerful approach than analysis of recruitment alone. Further, the earlier analysis of depensation used the Myers data base, which generally terminated in the early 1990's. Many stocks have been at low abundance in the last 15 years, and so the addition of more recent data may add considerably to the power of the analysis.

In this paper we will examine the history of catch and abundance for all of the major Atlantic cod populations to test the hypothesis that fishing alone is sufficient to explain the declines and failure to recover. We will look at the relationship between surplus production and biomass and the rate of surplus production and biomass. The simplest assumptions of fisheries population dynamics as contained in the logistic growth model or the standard age structured model [18] used in many agencies stock assessments is that the rate of production increases continuously as abundance declines. Under these "standard" assumptions we would expect stocks to recover rapidly when fishing pressure was reduced.

\section{MATERIALS AND METHODS}

The large data base on spawning stock abundance, recruitment, catch and fishing mortality rate assembled by Myers [19] has been extensively used for various forms of meta analysis of fish populations [1, 16, 17] but most of the data sets terminate in the early 1990s. Using the stock assessments conducted by ICES, DFO in Canada and NMFS in the U.S. we assembled a database on the catch, total stock abundance (usually the total biomass above a specific age), spawning stock abundance, recruitment and fishing mortality rate of each of the cod stocks. These are essentially the same stocks covered in the earlier Myers database, but the update includeds more recent data bringing most of the stocks up to 2002 or 2003. The Myers database was built primarily for the analysis of spawning stock and recruitment, but in our analysis we will be using only estimates of catch and total stock biomass. The addition of these later years of data provided information on periods of very low abundance for many stocks and should be highly informative about the causes of failure to recover.

We rearrange equation (1) to calculate surplus production for each year

$$
P_{y}=B_{y+1}-B_{y}+C_{y}
$$

and simply examine the history of surplus production and rate of surplus production for each stock.

\section{RESULTS}

Fig. (1) shows the relationship between surplus production and biomass for the 9 largest European stocks. A quadratic curve constrained to pass through the origin is fitted to the data for reference and would correspond to a logistic growth model. The stocks are arranged in order of their total stock size. Fig. (2) shows the relationship for North American stocks. Almost all stocks are now at or near historic low biomass. The NE Atlantic stocks all show continued surplus production, but that production is reduced due to overfishing. The two largest NE stocks, NE Arctic (panel a) and Iceland (panel b) stand out as being in better condition than the others.

The relationship between total stock biomass and surplus production for the North American stocks illustrates a diversity of histories. The impact of overfishing - reducing productivity for the largest stock, $2 \mathrm{~J} 3 \mathrm{KL}$, (panel a) and the $3 \mathrm{NO}$ stock (panel b) - is clear and these stocks are by almost any definition "collapsed." However, the 4TVN (panel d), 3PN4RS (panel c), and 4VSW (panel e) stocks all show a dramatic decline in surplus production at high abundance, while the 3PS stock (panel f) also show a decline, but not to zero productivity. Three other stocks, the two US stocks $5 Z$ (panel g) and 5Y (panel i), as well as the southern Canadian stock 4X (panel h), show a pattern similar to the northeast Atlantic stocks, i.e., continued surplus production, with several showing declining surplus productivity at lower stock abundances. The 5Y stock shows little decline in surplus production.

Fig. (3) shows the relationship between surplus production per unit of biomass and total stock biomass for $\mathrm{NE}$ Atlantic stocks. A linear fit to the data is shown for illustration, which would be the expected shape of the relationship under the logistic growth model. Fig. (4) shows the same relationship for the NW Atlantic stocks. The NE Atlantic stocks show a very consistent pattern of productivity per unit of biomass in the range of 0.4 to 0.6 at low stock biomass. Most NE Atlantic stocks show declining rates of productivity at higher biomass indicating some form of density dependence, with two small stocks (west of Scotland and the Celtic Sea) being the exceptions and showing no density dependence. The NW Atlantic stocks show quite different patterns. The pattern of the largest NW stock (2J3KL) shows a reasonably standard decline in productivity with declining biomass, with the rate dropping dramatically in the last year. Unfortunately there is no assessment data after 1991. The 3NO stock shows a curious pattern of declining productivity with lower biomass, while 4 stocks (panel c-f) show the pattern noted earlier of rate of productivity dropping to zero or close to it at a time of high abundance. The four smallest stocks (panels f-i) show patterns similar to the NE Atlantic stocks with evidence of density dependence but slightly lower rates of productivity at low abundance.

Fig. (5) shows the relationship between annual instantaneous fishing mortality rate from the published stock assessment and the annual population growth rate for the most 

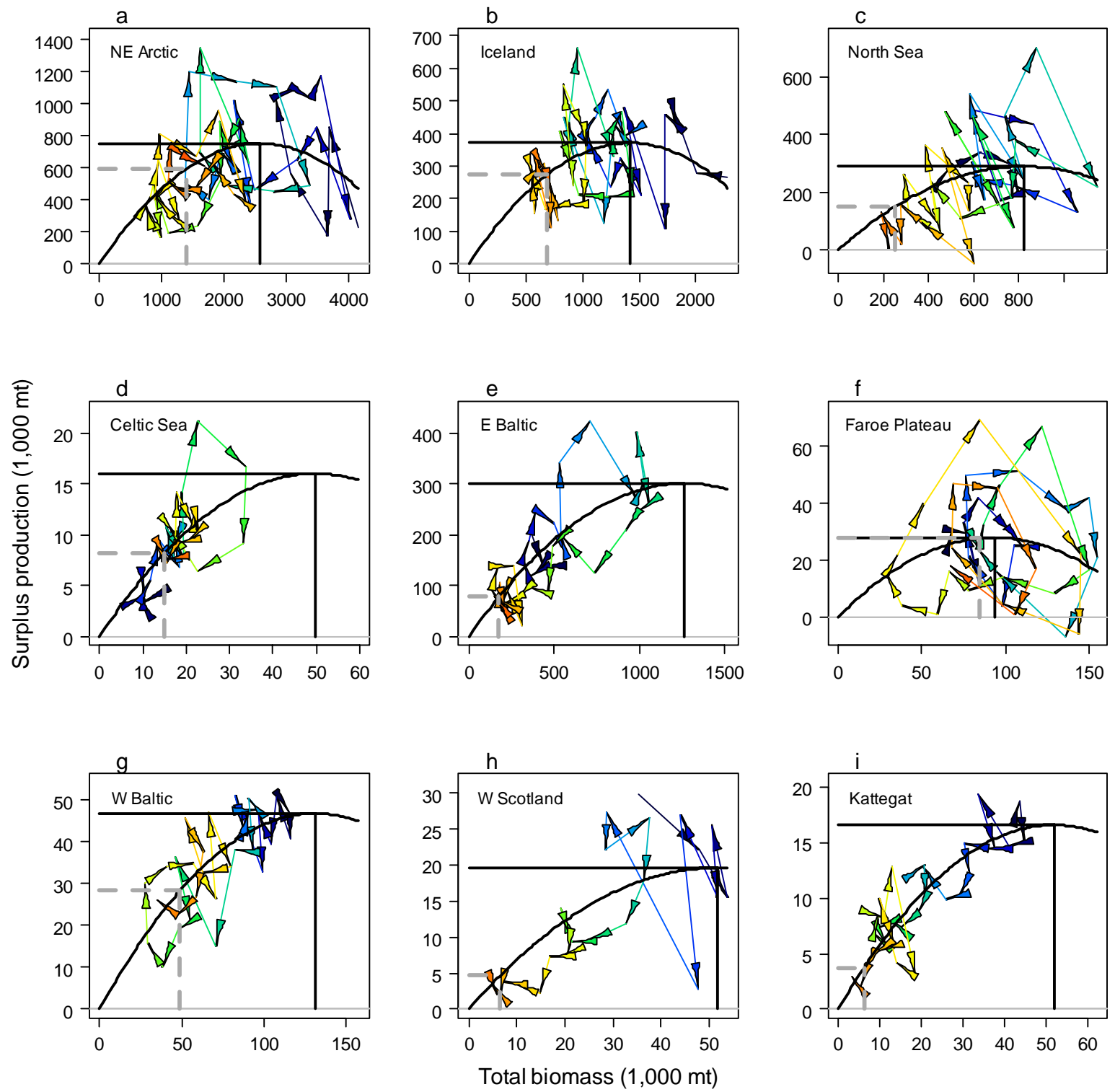

Fig. (1). Surplus production plotted vs total biomass in NE Atlantic cod stocks. A quadratic curve constrained to go through the origin is included for reference. The horizontal and vertical lines indicate the estimated point of maximum surplus production. Stock name in upper left hand corner of each panel. Colors indicate time trend of data with earliest data in blue and most recent data in red.

recent 10 years for the 9 largest NE Atlantic stocks. Here we see a clear relationship between of the intensity of exploitation and rate of increase. Any stocks fished with a F less than 0.7 were increasing while any fished with a $\mathrm{F}$ greater than 0.7 were decreasing.

\section{DISCUSSION}

The analysis of net productivity shows that all (9) of the NE Atlantic stocks, and four of the NW Atlantic stocks would recover rapidly if fishing pressure was reduced. These stocks maintain surplus production rates of 0.3 to 0.6 and if fishing pressure was reduced to a rate lower than that, the stocks would be expected to rebuild. There is no need to invoke any complex hypotheses of depensation, genetic changes etc.; excess fishing pressure is a totally sufficient explanation for their failure to rebuild.
In four of the other Canadian stocks the decline in productivity occurred at relatively high stock abundances, although continued fishing drove the stocks to low levels. Since the decline in productivity cannot be explained by fishing pressure, an environmental change seems the best explanation. Rothschild [9] has noted a coherent pattern of declining productivity in NW Atlantic cod stocks and ascribed it to environmental changes. Shelton et al. [20] have ascribed the decline in abundance and failure to increase of the Canadian stocks to a combination of declining somatic growth, increased natural mortality, declining recruitment and excess fishing pressure. While this decline in surplus production has been discussed for individual stocks [12], the dramatic and simultaneous decline in productivity at high abundance is not widely recognized. The fact that this occurred at high abundance across a wide geographic region provides convincing evidence against mechanisms that invoke depensation or evolutionary impacts of fishing. 

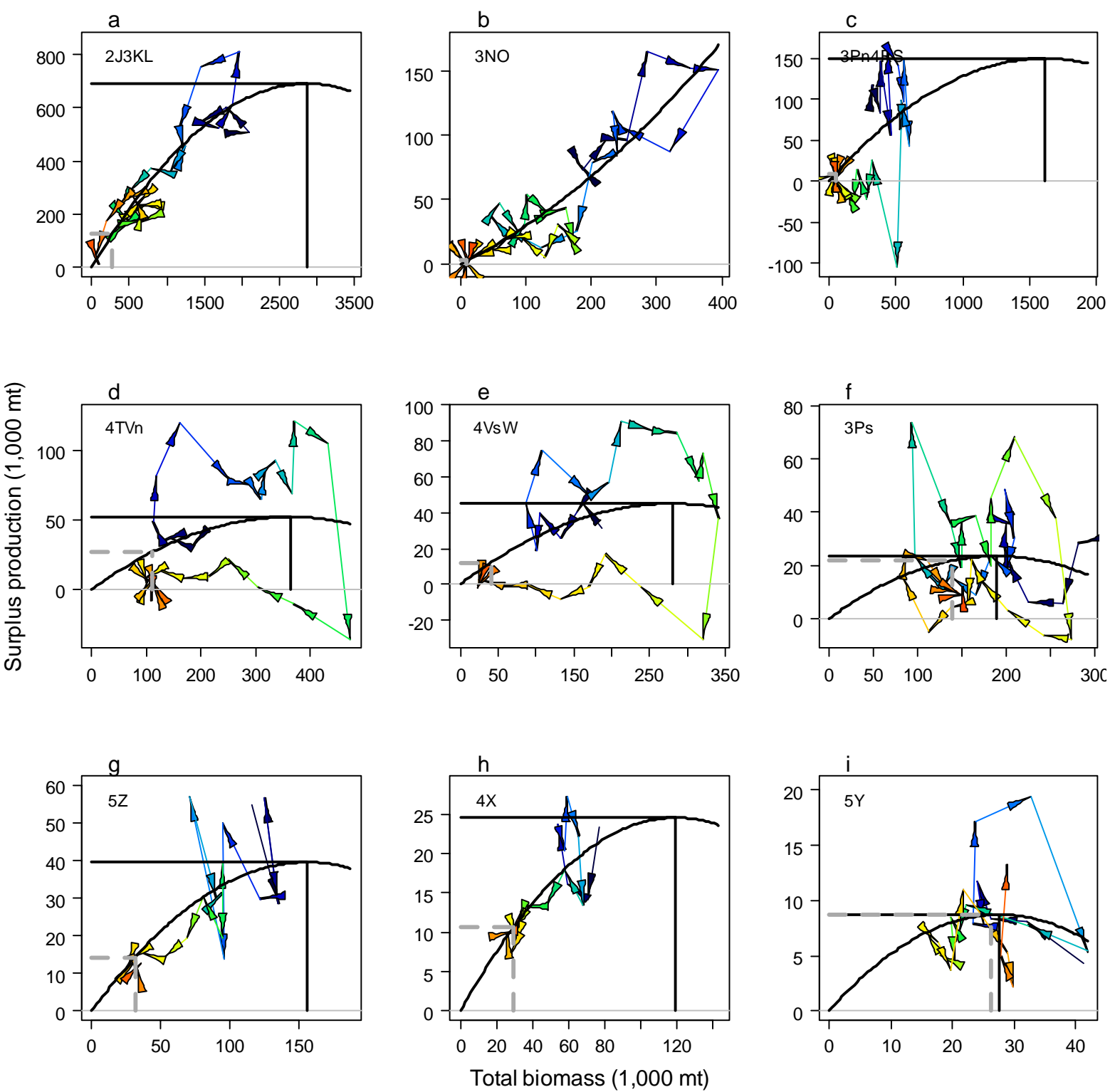

Fig. (2). Surplus production plotted vs total biomass in NW Atlantic cod stocks. A quadratic curve constrained to go through the origin is included for reference. The horizontal and vertical lines indicate the estimated point of maximum surplus production. Stock name in upper left hand corner of each panel. Colors indicate time trend of data with earliest data in blue and most recent data in red. Locations of the stocks are; 2J3KL Northern Newfoundland and Labrador, 3NO eastern Grand Banks, 3Pn4RS south of Newfoundland, 4TVn southern Gulf of St. Lawrence, 4VsW east of Nova Scotia, 3Ps south of Newfoundland, 5Z Georges Bank U.S., 4X Georges Bank Canada, 5Y Gulf of Maine.

The trends in the $2 \mathrm{~J} 3 \mathrm{KL}$ and $4 \mathrm{VNO}$ Canadian stocks suggest they were fished to low abundance, and then productivity collapsed. This could be the result of depensatory mechanisms, or could be caused by the same type of environmental change that affected the four stocks where production declined at high abundance. Other authors [21] have noted that a prime failure in the Canadian management system was to continue with fisheries, albeit often small scale fisheries, once stocks had declined.

There is considerable documentation of major ecosystem changes in eastern Canada including colder temperatures, and increases in predators including pelagic fishes and seals. Such major ecosystems changes are increasingly recognized to be characteristic of marine ecosystems, and in the long era of human exploitation these stocks presumably saw times of adverse environmental conditions. Recovery following such periods may require a sufficiently large reservoir of spawners. Thus it seems likely that the low abundance of the five Canadian stocks that have not recovered is a major cause of their failure to recover despite reduced fishing pressure. For example, if the Gulf of St. Lawrence stocks had not been fished to low abundance after their production collapsed, there would have been a much larger stock available from which to rebuild.

The dramatic decline in productivity of several Canadian stocks in the mid 1980s was not noted in the early publica- 

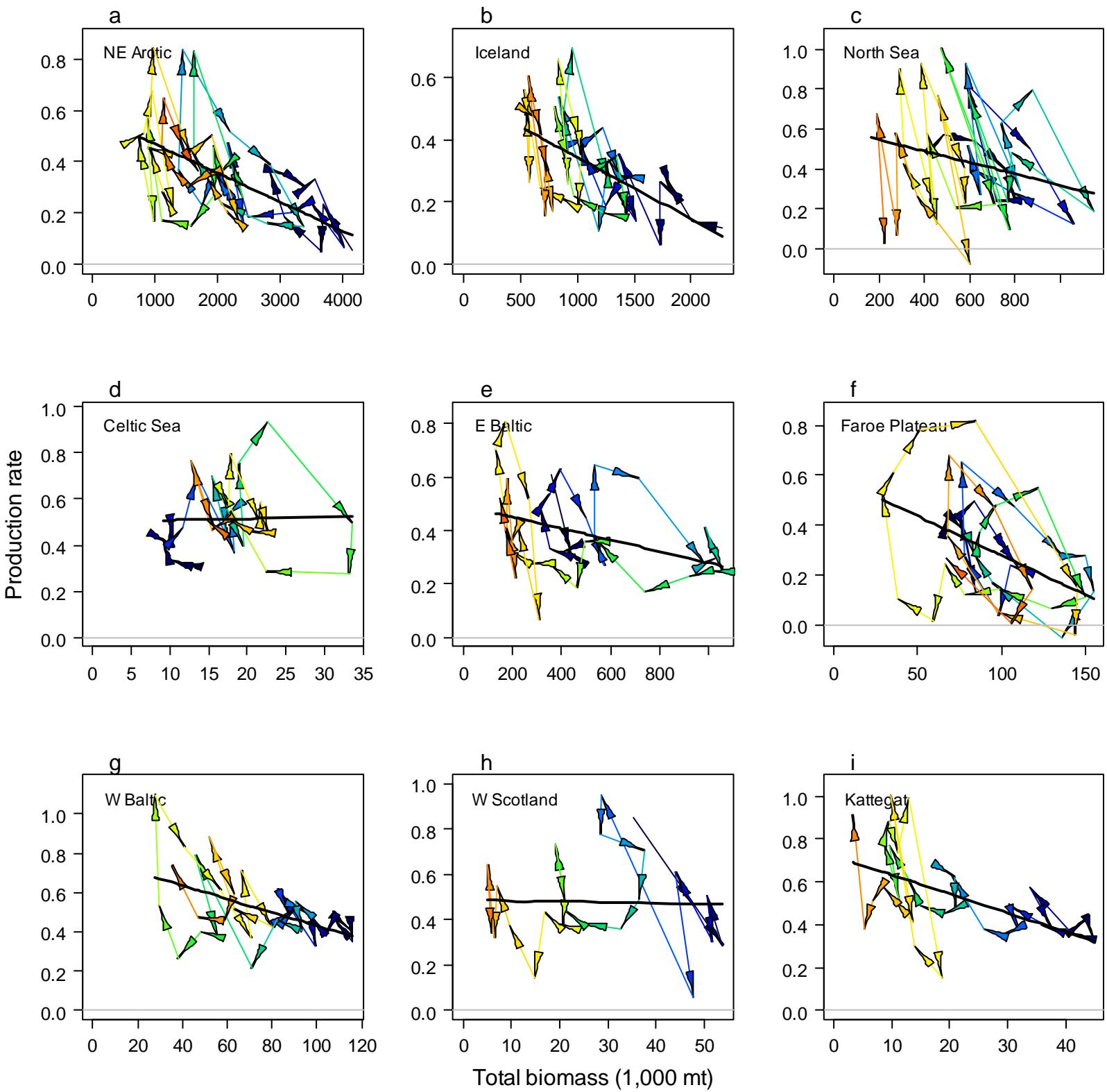

Fig. (3). The rate of surplus production plotted vs total biomass for NE Atlantic cod stocks. A linear fit to the data provided for reference. Colors indicate time trend of data with earliest data in blue and most recent data in red. Stock name in upper left hand corner of each panel.

tions considering cod declines [22], as most interest was focused on the early 1990s, when stocks reached low abundance, than on what happened in the mid 1980s, when productivity collapsed. Rice [21] showed that recruitment rate was lower in the 1980s than in the 1970s, but we have found no study that has explicitly looked at the changes in surplus production across a range of populations. The only explicit look at surplus production was [12] who did not look across the whole range of NW Atlantic populations and identified dramatic differences in rates of surplus production between most European stocks and the Canadian stocks. Cook et al. [23] suggested that the fishing mortality rates in Europe were non-sustainable, and our analysis a decade later suggests that fishing mortality rates in Europe remain too high to allow stock rebuilding. Indeed the ICES science groups have consistently called for reductions in fishing mortality rate on $\mathrm{NE}$
Atlantic cod, but the difference between the sustained rates of surplus production in the NE Atlantic and southern NW Atlantic stocks, and the decline in rates of surplus production in the northern NW Atlantic stocks is not widely appreciated. While numerous studies have now discussed environmental change in the NW Atlantic, the dramatic decline in net productivity in the mid 1980s for the four cod stocks in the Gulf of St. Lawrence and S of Newfoundland appears to be a singular event of productivity collapse at high abundance.

We conclude from our analysis that the majority of cod stocks would recover if fishing pressure was sufficiently reduced. The stocks that have failed to recover despite reduced fishing pressure appear to be trapped in states of low productivity, but in only two of these stocks did the onset of low productivity coincide with low stock abundance. For 

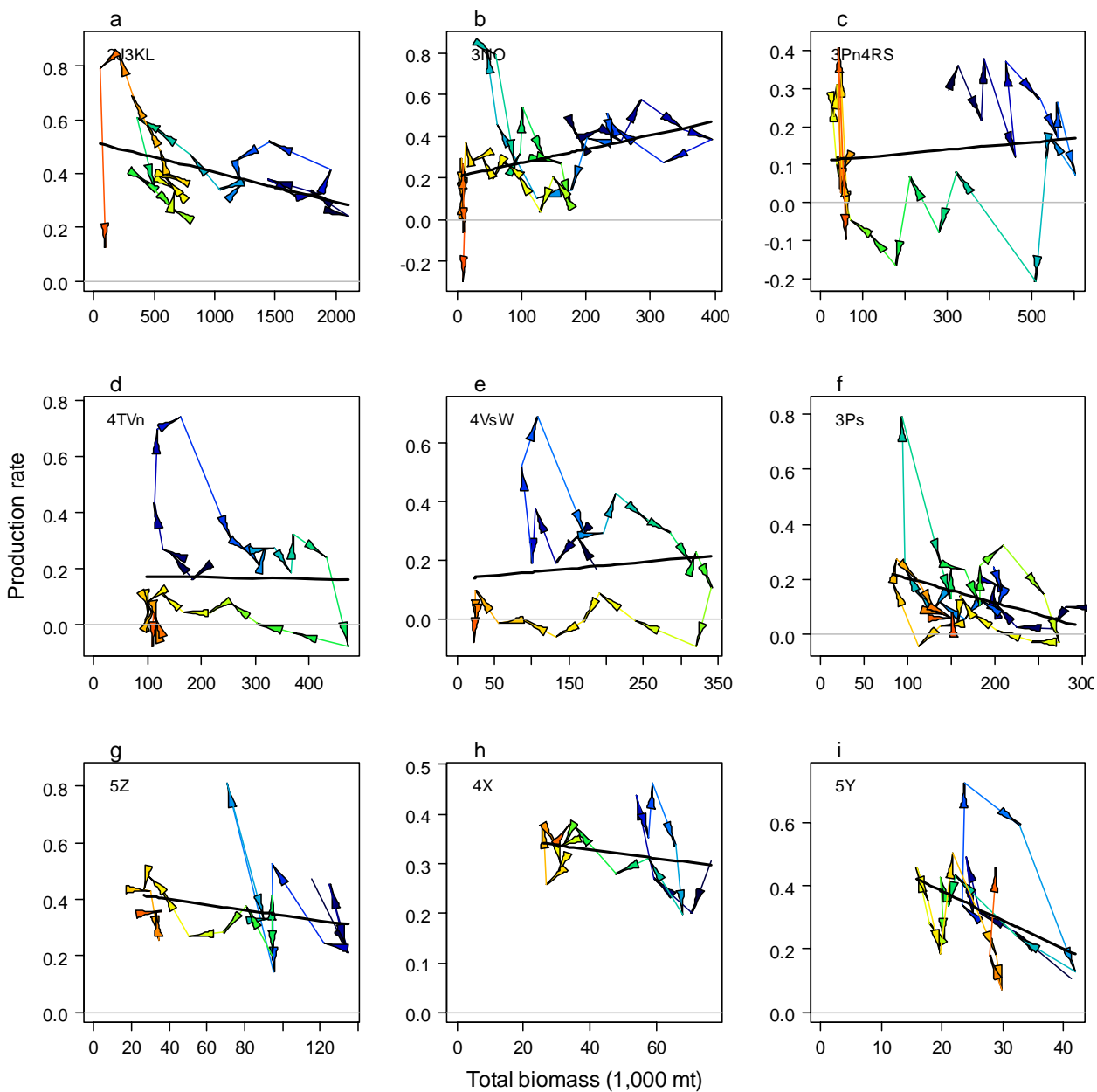

Fig. (4). The rate of surplus production plotted vs total biomass for Nw Atlantic cod stocks. A linear fit to the data provided for reference. Colors indicate time trend of data with earliest data in blue and most recent data in red. Stock name in upper left hand corner of each panel.

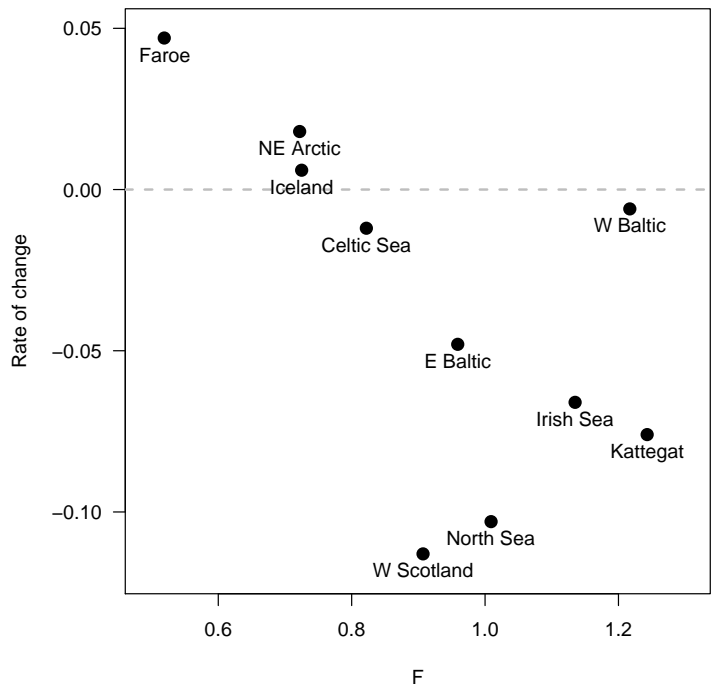

Fig. (5). Rate of change for NE Atlantic cod stocks versus fishing pressure. Each point represents the rate of change in the last 10 years of data plotted against average instantaneous fishing mortality rate $(\mathrm{F})$ from the stock assessment over the same period for each of the NE Atlantic cod stocks.

most cod stocks declines in abundance and failure to recover can be simply ascribed to fishing pressure, but the Canadian cod stocks exhibit remarkably different behavior and appear to be subject to a dramatically different environmental regime than the other stocks.

\section{ACKNOWLEDGEMENTS}

This work was supported by the Richard C. and Lois M. Worthington Professorship at the University of Washington.

\section{REFERENCES}

[1] Hilborn R. The frequency and severity of fish stock declines and increases. In: Hancock DA, Smith DC, Grant A, Beumer JP, Eds. Developing and sustaining world fisheries resources: Proceedings of the 2nd World Fisheries Congress: CSIRO Publishing: Collingwood, Victoria, Australia 1997.

[2] Hutchings J. Collapse and recovery of marine fishes. Nature 2000; 406: 882-5.

[3] Hutchings JA, Reynolds JD. Marine fish population collapses: Consequences for recovery and extinction risk. Bioscience 2004; 54: 297-309.

[4] Swain DP, Sinclair AF. Pelagic fishes and the cod recruitment dilemma in the Northwest Atlantic. Can J Fish Aquat Sci 2000; 57: $1321-5$.

[5] Fu CH, Mohn R, Fanning LP. Why the Atlantic cod (Gadus morhua) stock off eastern Nova Scotia has not recovered. Can J Fish Aquat Sci 2001; 58: 1613-23.

[6] Chouinard GA, Currie LG, Poirier GA, et al. Assessment of the southern Gulf of St. Lawrence cod stock. Canadian Department of Fisheries and Oceans: Ottowa 2005. 
[7] Olsen EM, Heino M, Lilly GR, et al. Maturation trends indicative of rapid evolution preceded the collapse of northern cod. Nature 2004; 428: 932-5.

[8] Swain DP, A.F. S, Hanson JM. Evolutionary response to sizeselective mortality in an exploited fish population. Proc R Soc Ser B 2007; 274: 1015-22.

[9] Rothschild B. Coherence of Atlantic cod stock dynamics in the Northwest Atlantic ocean. Trans Am Fish Soc 2007; 136: 858-74.

[10] Walters CJ, Kitchell JF. Cultivation/depensation effects on juvenile survival and recruitment: implications for the theory of fishing. Can J Fish Aquat Sci 2001; 58: 39-50.

[11] Dutil JD, Castonguay M, Gilbert D, Gascon D. Growth, condition, and environmental relationships in Atlantic cod (Gadus morhua) in the northern Gulf of St. Lawrence and implications for management strategies in the Northwest Atlantic. Can J Fish Aquat Sci 1999; 56: 1818-31.

[12] Dutil JD, Brander K. Comparing productivity of North Atlantic cod (Gadus morhua) stocks and limits to growth production. Fish Oceanogr 2003; 12: 502-12.

[13] Hilborn R. Calculation of biomass trend, exploitation rate, and surplus production from survey and catch data. Can J Fish Aquat Sci 2001; 58: 579-84.

[14] Jacobson LD, De Oliveira JAA, Barange M, et al. Surplus production, variability, and climate change in the great sardine and anchovy fisheries. Can J Fish Aquat Sci 2001; 58: 1891-903.
[15] Walters CJ, Hilborn R, Christensen V. Surplus production dynamics in declining and recovering fish populations. Can J Fish Aquat Sci 2008; 65: 2536-51.

[16] Myers RA, Barrowman NJ, Hutchings JA, Rosenberg AA. Population dynamics of exploited fish stocks at low population levels. Science 1995; 269: 1106-8.

[17] Liermann M, Hilborn R. Depensation in fish stocks: a hierarchic Bayesian meta-analysis. Can J Fish Aquat Sci 1997; 54: 1976-84.

[18] Punt AE, Hilborn R. Fisheries stock assessment and decision analysis: the Bayesian approach. Rev Fish Biol Fish 1997; 7: 3563.

[19] Myers RA, Blanchard W, Thompson KR. Summary of north Atlantic fish recruitment 1942-1987. Can Tech Rept 1990; No. 1743.

[20] Shelton PA, Sinclair AF, Chouinard GA, Mohn R, Duplisea DE. Fishing under low productivity conditions is further delaying recovery of Northwest Atlantic cod (Gadus morhua). Can J Fish Aquat Sci 2006; 63: 235-8.

[21] Rice JC, Shelton PA, Rivard D, Chouinard GA, Fréchet A. Recovering Canadian Atlantic cod stocks: the shape of things to come? International Council for Exploration of the Seas: Copenhagen 2003.

[22] Myers RA, Hutchings JA, Barrowman NJ. Hypotheses for the decline of cod in the North Atlantic. Mar Ecol Prog Ser 1996; 138 293-308.

[23] Cook RM, Sinclair A, Stefánsson G. Potential collapse of North Sea cod stocks. Nature 1997; 385: 521-2.

Received: December 03, 2008

(c) Ray Hilborn; Licensee Bentham Open.

This is an open access article licensed under the terms of the Creative Commons Attribution Non-Commercial License (http://creativecommons.org/licenses/by-nc/3.0/) which permits unrestricted, non-commercial use, distribution and reproduction in any medium, provided the work is properly cited. 